\title{
EL LIDERAZGO DE LA PROTAGONISTA EN ANATOMÍA DE GREY
}

\section{THE LEADERSHIP OF THE MAIN CHARACTER IN GREY'S ANATOMY}

Beatriz Peña Acuña: Universidad San Antonio. Murcia (España) beatriz-pa@gmail.com

\section{CURRÍCULUM VITAE}

Doctora por la Universidad de Alicante con mención europea en inglés con la máxima nota. Su director ha sido el catedrático Pedro Aullón de Haro. Actualmente ella es profesora contratada doctor en la Universidad Católica San Antonio. Imparte una asignatura de investigación científica "Observación sistemática" al Grado de Magisterio Infantil. Además es tutora de alumnos de Magisterio Infantil, Fisioterapia y Periodismo.

Su formación académica es multidisciplinar. Estudió primero una licenciatura en Filología Hispánica, y más adelante una Diplomatura humanística en la Universidad de Navarra. Actualmente cuenta con estudios de Periodismo. Ha cursado un curso a distancia de 540 horas de Especialización en Dirección y Producción de Cine, Video y Televisión por la Universidad Politécnica de Catalunya, ETSEIB. Se defiende en cinco idiomas: castellano, valenciano, inglés, francés, e italiano. Cuenta con publicaciones científicas en castellano, inglés e italiano. Ha recibido cursos pedagógicos, entre ellos el CAP, y asimismo otros cursos: periodísticos, de calidad, literarios y de ética profesional. 
Su experiencia como docente y orientadora es de doce años: siete en la universidad, y cinco en enseñanza media. También ha tenido práctica en preparación de acceso a estudiantes de modulo superior. A su vez ha obtenido experiencia laboral de gestión cultural de un Colegio Mayor.

Cuenta con una docena de publicaciones científicas en Journals como Japps, y otras revistas indexadas como Innovar, Vivat Academia o Frame. Ha defendido y publicado doce comunicaciones; ocho en congresos internacionales y de ellas tres han sido en inglés. Ha asistido a un total de 32 Congresos y 7 jornadas. También ha colaborado en la elaboración de una manual sobre tutorías, y cuenta con publicaciones on-line sobre cine.

Actualmente colabora en dos grupos de investigación. Un grupo competitivo "Humanismo-Europa" dirigido por el catedrático Pedro Aullón de Haro y otro, "Concilium", dirigido por el profesor titular David Caldevilla Domínguez. Precedentemente ha colaborado en un proyecto de investigación compuesto por profesores de diversas disciplinas de comunicación llamado: “Comunicación y Menores" de la UCAM.

Ha sido invitada a cuatro universidades para investigar. Ha realizado tres estancias de tres meses en prestigiosos departamentos de cine durante cuatro veranos (UEA de Norwich, Inglaterra, y NYU, N.Y., EE.UU., quinta mejor facultad estadounidense). Las otras dos son Queen Mary College de la University of London y el Tecnológico de Monterrey (México).

Posee amplia experiencia en la colaboración con los medios tanto en prensa, radio y televisión. Actualmente colabora en la tertulia de actualidad La siete, televisión regional de Murcia, desde noviembre 2009 www.7rm.es, también colabora con "Las damas de los martes" del programa Murcia y compañía, en Onda Regional (Murcia) desde Mayo 2008 www.orm.es. 
Forma parte de tres asociaciones como la Asociación Europea NEC'S European Network for Media and Cinema Studies, Red de Jóvenes Investigadores en Filosofía, Humanidades y Ciencias Sociales (RedJIF) y Asociación Española de Ciencia Política y Administración AECPA. Ha sido miembro de tribunal en el Certamen convocado por la Conserjería de Educación y cultura de Murcia. Le han concedido becas públicas para investigar y realizar sus estudios. Posee conocimientos de música y baile. Sus intereses y aficiones son amplios: artísticos, culturales y deportivos. Ha viajado por tres continentes: América del Norte, Europa meridional y Centro África.

\title{
RESUMEN
}

La disertación analiza los rasgos de liderazgo del personaje de Meredith Grey, protagonista de la serie televisiva Anatomía de Grey en los episodios de la primera temporada. Se describirán las cualidades de Meredith como persona y como residente en relación con otros compañeros suyos internos en el Hospital Seattle Grace. También se contemplan momentos de interacción en los que se descubre asimismo la capacidad de negociación que ésta posee en relación con otros personajes.

\section{PALABRAS CLAVE}

Liderazgo - Protagonista - Negociación - Serie de televisión - Anatomía de Grey

\begin{abstract}
The dissertation examines the leadership traits of the character of Meredith Gray, star of the television series Grey's Anatomy episodes of season one. Describe the qualities
\end{abstract}


of Meredith as a person and as a resident in relation to his fellow inmates at Seattle Grace Hospital. Also it is referred to moments of interaction in which one discovers also the negotiation power she possesses in relation to other characters.

\section{KEY WORDS}

Leadership - Leading - Negotiating - Television series - Grey's Anatomy

\section{ÍNDICE}

1. Definición de liderazgo

2. Descripción del personaje de Meredith Grey

3. Conclusiones

4. Bibliografía

\section{TEXTO}

\section{Definición de liderazgo}

Según el Diccionario de la Lengua Española, el "liderazgo" se especifica como la dirección, jefatura o conducción de un partido político, de un grupo social o de otra colectividad. El Diccionario de Ciencias de la Conducta lo precisa como las "cualidades de personalidad y capacidad que favorecen la guía y el control de otros individuos". El brasileño Idalberto Chiavenato subraya sobre el concepto: "Liderazgo es la influencia interpersonal ejercida en una situación, dirigida a través del proceso de comunicación humana a la consecución de uno o diversos objetivos específicos". 


\section{Descripción del personaje de Meredith Grey}

El personaje se presenta en el primer episodio con sus reflexiones con la que recibimos en forma de voz en off al comienzo y al final del capítulo, a través de lo que comentan los demás de ella y de forma directa a través de sus acciones y palabras por las que despunta sobre los demás. Entendemos el contexto en el que se sumerge como residente -el episodio se refiere a la cirugía- cuando recibe instrucciones por parte del Jefe de Cirugía, Richard Webber, de que deberán competir entre los residentes para merecer esa profesión. Les comenta nada más entrar en la sala de operaciones: "Mirad alrededor, esta es la competencia en la que serán puestos a prueba."

Llega una joven espasmódica al hospital y enseguida Meredith recibe la responsabilidad de vigilarla mientras los otros residentes realizan tareas menos interesantes o agradables, como Izzie Stevens que se dedica a efectuar tactos rectales. La protagonista descubre que el amante ocasional de la noche anterior es el Jefe de Neurocirugía, Derek Shepherd. La joven al principio muestra inseguridad con su paciente: "Soy doctora, pero no la de Katie. Iré a buscarla." Los residentes se reúnen en un descanso y conocemos a Meredith de forma indirecta. Comentan que su madre es una de las cirujanas pioneras. Entonces llega Meredith de mal genio porque Katie, su joven paciente, la ha sacado de sus casillas.

Después la protagonista muestra solidaridad con un compañero, George O’Malley, porque Preston Burke, el Jefe de cirugía cardiotorácica, le permite operar y los demás piensan que va a fracasar, cosa que efectivamente sucede. Cristina Yang, otra residente, no se muestra tan empática con George, al contrario, es competente pero competitiva, quiere ser la mejor en el programa de residentes. Enseguida Cristina explica que fue la primera de su promoción en Standford y aprovecha la oportunidad que se tercia para pedir a Miranda Bailey, su jefa inmediata, poder operar. 
Meredith destaca desde un principio como residente por tener los conocimientos necesarios, dar un diagnóstico acertado y un tratamiento adecuado cuando se encuentra por vez primera con otro residente, Alex Karev, sujeto que se muestra como pagado de sí mismo y que queda relegado en este caso por el mismo Jefe de Cirugía, Webber. Igualmente la protagonista aparece con suficiente competencia y capacidad de tomar decisiones cuando a su paciente le dan ataques múltiples, le da un paro cardiaco y Meredith consigue reanimarla. La situación a la que se enfrenta es poco tiempo y presión del personal que le pregunta qué deben ejecutar sobre la paciente. Derek aparece y la riñe: "Se supone que la vigilas. Vete, déjame con ella." Meredith después de la reanimación vomita por la tensión emocional.

Más tarde el neurocirujano reúne a los residentes y les pide que investiguen el diagnóstico. Meredith descubre que es un aneurisma mientras investiga el caso junto a Cristina y le confiesa que ha tenido relaciones con Derek. El neurocirujano elige a Meredith para que lo acompañe en la operación de Katie y entonces Cristina se enfada y llama "trepa" a su compañera. Meredith intenta reconciliarse con Cristina, pero ella la rechaza en un primer acercamiento.

Derek le aclara a Meredith que merece estar en la operación porque le ha salvado a la joven cuando tenía ataques múltiples. Meredith le cuenta que cuando le dijo a su madre que quería estudiar medicina la cirujana la desanimó diciéndole que no tenía madera y que lo dejara. Le confiesa a Derek que le ha gustado mucho estar operando. Cristina espera a Meredith después de la operación y hacen las paces. Después la protagonista visita a su madre que está en una residencia con Alzheimer y le dice que se va a quedar con la casa que pertenecía a su madre.

En el segundo episodio titulado "todo son barreras" Meredith hace hincapié en la dificultad que supone la convivencia y las relaciones sociales: “Las más difíciles son 
con los demás. No te sirve de nada intimar." En este episodio la protagonista se atreve a pedir una operación menor a Miranda Bailey, la nazi. La protagonista enseguida se pone en acción porque ingresa una joven violada y brutalmente golpeada. La violentada conservaba parte del cuerpo del criminal en su boca y le toca a Meredith custodiarlo como prueba del delito del agresor. Las relaciones entre los demás comienzan a ser difíciles. Hay rivalidad entre Shepherd y Burke porque ambos aspiran a llegar a ser Jefes de Cirugía cuando Webber, jefe de Cirugía, se retire, y Cristina compite con Alex en las consultas. Meredith está afectada por el caso de la violada, y George se da cuenta. Le propone ir a la planta de Pediatría a ver bebés para relajarse un poco. Meredith se percata que hay un niño cianótico y se lo comenta a la residente en pediatría, pero ésta se enfada porque siente que se ha inmiscuido en sus competencias. La joven residente consigue que Preston Burke se haga cargo del neonato y lo salvan. No obstante, Burke riñe a Meredith por saltarse los protocolos. La protagonista acaba hablando con la joven residente de Pediatría que le reconoce que tenía miedo.

Más tarde Derek le cuenta a Meredith que ha estado velando a la violada porque tiene cuatro hermanas y si él estuviera así ellas lo visitarían. La joven, en cambio, cuando éste se interesa por su madre no le cuenta la enfermedad grave de su madre. La protagonista finalmente acepta que Izzie y George vivan con ella en su casa porque son sus buenos compañeros y se lleva bien con ellos; escoge personalidades que no le van a causar problemas. La protagonista finaliza el episodio comentando: "Si te arriesgas, las vistas desde el otro lado son espectaculares."

En el tercer episodio Meredith sigue inmersa en la competición. Aparece compitiendo con Alex Karev por un paciente, Viper, que se ha golpeado. La joven residente recomienda al cliente que se haga un TAC, pero el paciente no quiere y se marcha del hospital por su cuenta y riesgo. Izzie solicita ayuda a Meredith para reanimar a un paciente en coma. Las dos negocian para que sea operado, intentan 
convencer a Burke, pero éste se niega. Entonces se les ocurre que el comatoso puede ser donante múltiple de órganos. Entonces, Cristina Yang se siente incapaz de negociar con los familiares del comatoso hasta que Bailey la anima a hacerlo: "Eres una persona y tienes pacientes."

Meredith descubre que Viper vuelve al hospital ensangrentado y se lo lleva al quirófano. Derek la busca para pedirle salir. Ella reconoce que tiene problemas con los compañeros de piso-porque compiten por la habitación-, familiares -por su madre-, y sentimentales- porque duda qué hacer con Derek. Al final sobre la competición social ella concluye que "no hay ganadores, ni perdedores, gana el que salva vidas." En este capítulo muestra que como médico tiene valentía, prudencia y que sabe tomar decisiones a tiempo.

El cuarto capítulo se titula "Intimidad". George le exige a Meredith que imponga unas normas en la casa porque Izzie se pasea en ropa interior y se mete en el baño mientras él se ducha, comportamiento que le molesta bastante.

La protagonista se encuentra con el caso de un paciente, Jorge, que ha sufrido un accidente y tiene clavos clavados en el cerebro. Derek lo opera, pero descubren que tiene alojado un tumor cerebral.

Meredith es eficaz en el diagnóstico porque sabe ser cercana con los pacientes y le acaban dando información útil para determinar el problema. En este caso trata de negociar con el paciente y, sobre todo, con la esposa de éste para que cambien de opinión cuando la elección que el paciente toma es una operación en la que probablemente perderá la memoria. Ella le aconseja a su mujer que se incline por un tratamiento a largo plazo del tumor porque tiene la experiencia -por su madre con Alzheimer- de que la pérdida de memoria puede incapacitar las relaciones interpersonales, pues su madre a veces no la recuerda como hija. 
En vistas de la resolución de esta pareja que prefieren perder los recuerdos de la anterior relación que han tenido a cambio de alargar la vida de Jorge, Meredith llega a entender que cada uno posee una concepción personal de lo que abarca esa intimidad, entonces llega al final a la reflexión de que: "Puede que las reglas de la intimidad, las tengas que definir tú sola".

En el quinto capítulo Meredith se plantea la cuestión de la "responsabilidad". La invitan a una operación de corazón y ella sostiene la víscera mientras están operando. Como lleva mucho rato, da una cabezada y entonces se percata de que ha apretado mucho el corazón y de que se ha rasgado el dedo de su guante. Preocupada se lo confiesa a O’Malley que es el que está más pendiente de ella y está en el momento oportuno. Ella le cuenta confidencialmente sus dudas acerca de que el corazón de la paciente esté dañado por su culpa.

La recuperación de la operación de la paciente es desfavorable, entonces Meredith le confiesa con valentía a Burke delante del marido de la paciente que puede haber rasguñado el corazón. Webber, el jefe de Cirugía quiere hablar con Meredith.

Derek se acerca dos veces a la protagonista para que ella se desahogue con él, pero ella no aprovecha la oportunidad. Ella intenta hablar con el esposo de la paciente que fallece porque éste ha planteado un pleito al hospital. En la conversación ella extrae el dato de que la paciente adelgazó muy rápido. Al fin el Jefe de Cirugía le da otra oportunidad a Meredith de seguir en el programa de residentes porque se descubre en la autopsia que la pared del corazón de la paciente estaba dañado al estar debilitado por adelgazar tan apresuradamente.

El capítulo sexto Meredith se plantea el tema del "miedo". Aparece en el hospital una paciente con un tumor enorme, muy desarrollado en el vientre. Se trata de un caso 
complicado en el que anhelan intervenir los residentes. Alex consigue poder operar este caso y Cristina se lo pide a Burke después de que han comenzado una relación sentimental.

Derek favorece a Meredith en un caso y Bailey le comunica al jefe de neurocirugía que fastidiará a la residente para compensar este favoritismo.

La protagonista es convincente con un paciente de Parkinson avanzado y lo disuade de ser operado para mejorar su calidad de vida, aunque la operación supone un riesgo. Meredith trata de negociar con Bailey y justifica que la relación sentimental con el neurocirujano comenzó la noche anterior a que empezara el programa de residentes; no hubo malicia en comenzar una relación con él y no pretendía sacar ventajas en el trabajo a través de esta relación. La jefa de residentes, en cambio, no deja que ella se justifique. En otro momento Shepherd trata de protegerla, pero ella no se deja. Ella declara: “Me he metido en este lío y saldré de él (la cirugía)".

Al final Meredith Grey vence su miedo a salir con Derek Shepherd a pesar de que es políticamente incorrecto: es su jefe en el trabajo y le puede acarrear problemas con los demás. Cuando George decide pedirle salir a Meredith y va a buscarla a su cuarto descubre que ella no pasa la noche allí, porque la residente está con el neurocirujano. En cambio, Cristina y Burke no aclaran los términos de su relación porque ella no quiere establecer nada serio por el momento con él. Cuando Preston le pregunta: "¿Qué hay entre tú y yo?". Ella le contesta con una pregunta: “¿Eres el tipo de hombre que necesita una definición?".

En el episodio séptimo Meredith esconde su relación con el neurocirujano. El capítulo se titula "Liderazgo". A pesar de que ella mantiene la relación en secreto, Bailey lo sabe y le hace la vida imposible en el hospital. La protagonista resiste las 
dificultades que interpone su jefa porque piensa que no hace mal a nadie teniendo esta relación y tampoco se deja influir por las habladurías.

Meredith consigue diagnosticar que una joven paciente tiene problemas porque se ha realizado una operación ilegal previa de estómago que se ha complicado. Izzie se enfada con la protagonista porque piensa que Shepherd la favorecerá dándole este caso, pero cuando habla con Meredith se da cuenta que ésta tiene sentimientos sinceros respecto a Derek.

La joven residente ayuda a resolver el caso de la joven paciente y vuelve a mostrar mucha fortaleza otra vez porque es capaz de enfrentarse a la madre que ha presionado mucho a su hija con la cuestión de estar delgada hasta el punto de que denuncia a ésta a los servicios sociales.

El octavo capítulo trata sobre la fe y la confianza en los demás. En este capítulo los otros personajes cobran mayor protagonismo. Cristina descubre que está embarazada de Burke, no se lo comenta a él y decide abortar.

Meredith quiere saber más cosas de Derek después de unos días de relación con él. Él le pide que sea en esto flexible, pero no le cuenta ni donde vive, ni nada personal. Ella se incomoda un poco. El neurocirujano la cita para un caso de un hombre que no siente los pies. Al final del capítulo, los dos hablan de tener fe y confianza el uno en el otro. Él le enseña donde vive y le pide que tenga confianza en él.

El noveno capítulo versa sobre los "secretos". Meredith es capaz de contarle a Derek la enfermedad de su madre. Justo cuando él se decide a tener una conversación para contarle que está separado, aparece su mujer en el hospital, Addison, y le espeta a ella que "tú debes de ser la que se acuesta con mi marido". Meredith se queda de piedra porque no lo sabía. 
Izzie y Cristina muestran arrestos cuando deciden hacer una autopsia a un recién fallecido por su cuenta y riesgo a espaldas de Bailey que las riñe. Gracias a eso descubren que el paciente tiene una enfermedad hereditaria y que su hija lo puede sufrir también.

En el hospital Webber decide dar una sesión de formación a los empleados del hospital porque hay contagio de sífilis, George se ha contagiado de una enfermera que antes mantuvo relaciones con Alex. Cristina y Burke descubren que son fieles a la relación que mantienen en la cola de la revisión.

\section{Conclusiones}

Los rasgos de liderazgo de la protagonista presentados por orden son los siguientes. Primero, advertimos la madurez interior que adquiere a través de la experiencia gracias a los comentarios de voz en off. Segundo la joven residente se muestra solidaria con un compañero. Tercero, la joven acierta por sus conocimientos en el diagnóstico y tratamiento de dos pacientes en una primera intervención. Por otro lado, ésta sabe reaccionar y tomar decisiones bajo presión cuando reanima a la paciente. No hace uso de la fama de su madre, una cirujana famosa. Cuarto, la chica muestra capacidad de negociación cuando busca reconciliarse con su compañera Cristina. Cuarto, ésta mantiene una alta ética respecto a los pacientes, se arriesga y es valiente con tal de salvar o curar a los pacientes. Quinto, es prudente en la práctica médica, supervisa cada protocolo con cuidado. Sexto, la residente es flexible y abierta a otras soluciones a un mismo problema, respeta las decisiones de los demás. Séptimo, ésta se muestra responsable de sus acciones y reconoce sus errores con valentía. Octavo, la protagonista trata de resolver por sí misma sus asuntos y no quiere dejarse proteger. Noveno, ésta es capaz de arriesgarse a entrar en una relación 
sentimental aunque tenga dificultades en su trabajo. Décimo, la joven cirujana muestra fortaleza, resiste las dificultades que le pone su jefa, Bailey. Undécimo, ésta sabe mostrar confianza y fe en los demás. Duodécimo, el resto de residentes confía en la actuación médica de Meredith. Todos estos rasgos consiguen que Meredith merezca el liderazgo y sobresalga entre sus compañeros de tal modo que se conforma como una joven promesa para el Hospital Seattle Grace.

El liderazgo de la protagonista sin embargo, no se presenta de forma idealizada, sino de modo posmoderno porque muestra sus debilidades con más realismo: por ejemplo, le afecta el sufrimiento de los demás, duda algo en ocasiones a la hora de tomar decisiones que le afectan personalmente, tarda en reconocer, enfrentarse y revelar los problemas emocionales que le afectan directamente -como es la cuestión de su madre con Alzheimer-, escoge compañeros de piso que con los que piensa que no va a tener problemas y no se arriesga a conocer compañeros nuevos.

\section{Bibliografía}

AAVV, Diccionario de la lengua española, Espasa-Calpe, Madrid, 1984

ARANA, J., Recursos humanos en la empresa moderna, Gestión 2000, Barcelona, 2005

BLANCO, J., Del autismo a la comunicación. La nueva gestión de recursos humanos, Gestión 2000, Aedipe, Barcelona, 1995

CHIAVENATO, I., Administración de Recursos Humanos, MCGraw Hill, Santa Fe de Bogotá, 1993. 
CLAVER CORTES, E., Los recursos humanos en la empresa. Un enfoque directivo, Civitas, Madrid, 1996

DOLAN, S., SCHULER, R., VALLE CABRERA, R., La gestión de los recursos humanos, McGraw-Hill, Madrid, 1997

GASALLA, J.M., La nueva dirección de personas, Pirámide, 1998

LE BOTERFG, G., Ingeniería de las competencias, Gestión 2000, 2001

LOVART, P., Gestión de recursos humanos, Gestión 2000

PAÑOS ALVAREZ, A. y ROJO VILLADA, P. A., Organización y gestión de empresas informativas, Diego Marín, Murcia, 2008.

PEÑA ACUÑA, B., Rasgos de liderazgo en los directivos de Anatomía de Grey, Revista Frame, revista de cine, número 7.

PUCHOL, L., Dirección y gestión de recursos humanos, Díaz de Santos, Madrid, 2000 .

WOLMAN B., Diccionario de ciencias de la conducta, México DF, Mx Trillas, 1984. 